\title{
PHENOLIC COMPOUNDS FROM THE RHIZOMES OF INDONESIAN Curcuma amada
}

\author{
P. Sugita ${ }^{1}$, M. Amalia ${ }^{2}$, H. Dianhar ${ }^{3}$ and D. U. C. Rahayu ${ }^{2, \bowtie}$ \\ ${ }^{1}$ Department of Chemistry, Faculty of Mathematics and Natural Sciences (FMIPA), IPB \\ University, Bogor 16680, Indonesia \\ ${ }^{2}$ Department of Chemistry, Faculty of Mathematics and Natural Sciences (FMIPA), Universitas \\ Indonesia, Depok 16424, Indonesia \\ ${ }^{3}$ Chemistry Study Program, Faculty of Mathematics and Natural Sciences (FMIPA), Universitas \\ Negeri Jakarta, Jakarta 13220, Indonesia \\ ${ }^{\bowtie}$ Corresponding Author: dyahutamicr@sci.ui.ac.id
}

\begin{abstract}
The rhizomes of Curcuma amada (Zingiberaceae), locally recognized as Temu Mangga (Mango Ginger), are usually consumed as herbal medicine since they show antibacterial anticancer antihyperglycemic, and antitubercular activities. Many reports were also explored for its terpenoid contents, but the information of phenolic compounds from $C$. amada is still limited. This research aims to isolate phenolic compounds from the ethanol extract of $C$. amada rhizomes grown in Bogor, Indonesia. C. amada rhizomes were macerated in ethanol to give brownish-black crude extract (5.084\%, $\mathrm{w} / \mathrm{w})$. The crude extract then was fractionated and purified using a sequence of chromatographic techniques to afford two isolated fractions, $\mathrm{C} 1$ and F1. According to UV-Vis, FTIR, and LC-MS spectral data, the C1 and F1 fractions were identified as curcumin and naringenin, respectively.
\end{abstract}

Keywords: Curcuma amada, Curcumin, Mango, Ginger, and Naringenin.

RASĀYANJ. Chem., Vol. 14, No.4, 2021

\section{INTRODUCTION}

Curcuma amada belongs to the Curcuma genus and Zingiberaceae family, which is popular as an herbal plant. This vegetal is generally identified as mango ginger and from east Indian origin. This native Indian plant has spread widely to several countries in Asia, including Indonesia, Australia, and America. ${ }^{1}$ C. amada is a unique plant because its morphology is similar to ginger (Zingiber officinale) but has a mango (Mangifera indica) aroma. Because of this uniqueness, C. amada is also locally acknowledged as Temu Mangga in Indonesia. C. amada is commonly used as a seasoning for making pickles, sauce, curry, candy, salad, and flavor because of its distinctive aroma. C. amada is also known as a source of certain minerals and starches so that this plant can be used as a medicine, cosmetics, dye, and as nutraceutical. ${ }^{1,2}$ Several bioactivities of $C$. amada rhizome have been investigated, including antibacterial, antioxidant, anticancer, antihyperglycemic, anti-inflammatory, and antiallergic properties. ${ }^{3}$

According to phytochemical studies, the rhizomes of $C$. amada are rich natural source terpenoids, and small quantities of flavonoids, alkaloids, saponins, tannins, carbohydrates, proteins, and steroids. The essential oil of $C$. amada from the local wet market in Kuantan, Pahang was in abundance of monoterpenes (31.44\%), sesquiterpenes (52.67\%), and small quantities of diterpenes $(15.89 \%){ }^{4}$ In addition, the chemical investigation on the fractions of $n$-hexane and ethyl acetate extracted from Yogyakarta $C$. amada resulted in seven terpenoids classified as labdane derivatives. ${ }^{3}$ The major component of essential oil of $C$. amada nearby Sungai Nibong, Penang was myrcene (78.6\%). ${ }^{5}$ Moreover, the essential oil of dried rhizomes of C. mangga purchased from Kiza Herbs, Malaysia, was dominated by monoterpenes $78.6 \%$, sesquiterpenes $4.8 \%$, and diterpenes $5.9 \%$ with the major components were identified as $\beta$-pinene $(14.6 \%)$ and myrcene $(46.5 \%){ }^{6}$ Three terpenoids from chloroform extract of $C$. amada rhizomes obtained from a local market in Mysore, India was successfully identified..$^{7-8}$

Based on several literature studies, knowing predominant terpenoids, C. amada rhizomes attract scientists' attitude to examine novel terpenoids or essential oils from this herbal. ${ }^{3-8}$ However, there have been few 
studies on the phenolic compounds found in Indonesian C. amada rhizomes. This research isolated and characterized phenolic compounds from ethanol crude extract of $C$. amada rhizomes grown in IPB University, Indonesia. Identifying phenolic compounds from Indonesian $C$. amada rhizomes could major impact Indonesian phytochemistry.

\section{General Procedures}

\section{EXPERIMENTAL}

Chemicals used for isolation were ethanol (EtOH), methanol $(\mathrm{MeOH}), n$-hexane, and ethyl acetate (EtOAc) in technical grade (CV. Satya Darmawan). Thin-layer chromatography (TLC) for monitoring fractions was executed on $0.25 \mathrm{~mm}$ thickness coating of silica gel $60 \mathrm{GF}_{254}$ plates (Merck) and envisioned below ultraviolet (UV) light (254 and $366 \mathrm{~nm}$ ). Fractionation and purification were conducted by using various silica gel obtained from Merck, i.e. Si $60 \mathrm{G}$ (packing column) and Si 60 0.2-0.5 mm (adsorbing sample) in vacuum liquid chromatography (VLC), Si $60(0.063-0.200 \mathrm{~mm})$ in column chromatography $(\mathrm{CC})$, and $\mathrm{Si}$ $60 \mathrm{PF}_{254}$ containing gypsum in preparative-TLC (p-TLC). The isolated fractions were characterized using Ultraviolet-Visible (UV-Vis) Shimadzu UV-2450 in MeOH spectrophotometric grade (Merck), Fourier Transform-InfraRed (FTIR) Shimadzu IR Prestige 21 in KBr (Merck), and Liquid Chromatography-Mass Spectrometry tandem Mass Spectrometry (LC-MS/MS) in MeOH with the addition of formic acid (Merck). LC-MS/MS parameters were adapted from previous research. ${ }^{9}$

\section{Plant Material}

The rhizomes of $C$. amada were purchased from Trop. BRC garden LPPM-IPB University, West Java, Indonesia in January 2019.

\section{Extraction, Phytochemical Investigation, and Isolation of $\boldsymbol{C}$. amada Rhizomes}

Finely ground air-dried $C$. amada rhizomes $(1.0 \mathrm{~kg})$ were $3 \times 24 \mathrm{~h}$ macerated with EtOH. The solvents were vaporized beneath reduced pressure to yield $50.73 \mathrm{~g}$ brownish-black crude extracts $(5.084 \%$, w/w). The extracts were subjected to phytochemical screening to preliminary investigate the presence of flavonoid, tannin, terpenoid, steroid, alkaloid, and saponin following standard procedures. ${ }^{10}$ Around $20 \mathrm{~g}$ of ethanol extracts then were continued to VLC separation and eluted with various solvents of $n$-hexane, $n$ hexane/EtOAc (8:2 to 3:7, v/v), EtOAc, and MeOH to give 21 fractions (A1-A21). Fractions A10-A12 (1.5 g) were mixed based on TLC profiles similarity and further fractionated by CC using gradient solvent of $n$ hexane/EtOAc, EtOAc, and MeOH to obtain 11 fractions (B1-B11). Fraction B3 (500 mg) then was purified by p-TLC ( $n$-hexane: EtOAc 5:5, v/v) to afford yellow to orange solid $(20 \mathrm{mg})$ with one yellow spot in TLC (fraction C1). Moreover, since fractions B5-B7 showed similar TLC patterns, these fractions were combined and mentioned as fraction D $(530 \mathrm{mg})$. Fraction $\mathrm{D}$ than was fractionated by CC using the same condition with fraction A10-A12 to gain 3 fractions (E1-E19). Fraction E4 (160 mg) was further purified using p-TLC ( $n$-hexane:EtOAc 4:6, v/v) to obtain fraction F1, a pale-yellow solid (10 mg) with one purplespot in TLC. Fraction C1 and F1 were then elucidated by using UV-Vis, FTIR, and LC-MS and identified as curcumin (1) and naringenin (2), respectively.

\section{Physical Properties and Spectral Data of Isolated Compounds}

Fraction Cl curcumin (1): yellow-orange solid; TLC $\left(\mathrm{R}_{f}\right) 0.73$ ( $n$-hexane:EtOAc 5:5, v/v); UV-Vis $(\mathrm{MeOH}) \lambda_{\max }(\mathrm{nm}): 259$ (benzoyl) and 420 (curcuminoid); FTIR $(\mathrm{KBr}) v\left(\mathrm{~cm}^{-1}\right): 3300(\mathrm{O}-\mathrm{H}), 3050(\mathrm{C}-\mathrm{H}$ $\left.s p^{2}\right), 2900-2800\left(\mathrm{C}-\mathrm{H} s p^{3}\right), 1718(\mathrm{C}=\mathrm{O}), 1626(\mathrm{C}=\mathrm{C}$ alkene $), 1508(\mathrm{C}=\mathrm{C}$ aromatic $), 1282(\mathrm{C}-\mathrm{O}-\mathrm{C}$ ether $)$; and LC-MS/MS (MeOH-HCOOH): LC rt $8.71 \mathrm{~min}, \mathrm{MS}(70 \mathrm{eV}, \mathrm{m} / \mathrm{z}): 369.1335[\mathrm{M}+\mathrm{H}]^{+}$(base peak), 353.2192, 335.2071, 285.1118, 253.0864, 245.0811, 193.0652, 177.0548, 149.0597, 145.0285, 135.0364, $117.0335,91.0539\left(\mathrm{C}_{21} \mathrm{H}_{20} \mathrm{O}_{6}\right)$.

Fraction F1 naringenin (2): pale-yellow solid; TLC $\left(\mathrm{R}_{f}\right) 0.43$ ( $n$-hexane:EtOAc 4:6, v/v); UV-Vis (MeOH) $\lambda_{\max }(\mathrm{nm}): 283$ (benzoyl) and 334 (cinnamoyl); FTIR $(\mathrm{KBr}) \vee\left(\mathrm{cm}^{-1}\right): 3336(\mathrm{O}-\mathrm{H}), 2961\left(\mathrm{C}-\mathrm{H} s p^{2}\right), 2927-$ $2872\left(\mathrm{C}-\mathrm{H} \mathrm{sp} p^{3}\right), 1730(\mathrm{C}=\mathrm{O}), 1681$ and $1617(\mathrm{C}=\mathrm{C}$ aromatic), 1274 (C-O-C ether); LC-MS/MS (MeOH$\mathrm{HCOOH}): \mathrm{LC}$ rt $5.79 \mathrm{~min}, \mathrm{MS}(70 \mathrm{eV}, \mathrm{m} / \mathrm{z}): 273.1168[\mathrm{M}+\mathrm{H}]^{+}, 257.1393,239.1284,229.1432,217.1591$, 201.0760, 175.0600, 161.0959, 157.1009, 135.0804, 119.0857 (base peak), 107.0855, 91.0545, 79.0544 $\left(\mathrm{C}_{15} \mathrm{H}_{12} \mathrm{O}_{5}\right)$. 


\section{RASĀYAN J. Chem.}

Vol. 14 | No. 4 |2686-2691| October- December | 2021

\section{RESULTS AND DISCUSSION}

In the present work, Indonesian C. amada rhizomes grown in Bogor, West Java was successfully extracted by maceration in ethanol. Phytochemical investigation of ethanol extract was conducted to reveal the main group of secondary metabolites and depicted in Table 1. According to Table 1, a total of six phytochemicals was screened, of which five were presented, i.e. flavonoid, tannin, terpenoid, alkaloid, and saponin. Moreover, in general, similar phytochemicals were found in the same species of different origins. Little differences in phytochemical constituents might be due to different geographical areas, climates, and surrounding environments. ${ }^{9-10}$ This finding suggests that the $C$. amada rhizomes have extensive phytochemical potential and exhibit optimistic results for therapeutic chemical constituents.

Table-1: A preliminary phytochemical screening of ethanol extract of Indonesian C. amada rhizomes (this research) and comparison with previous research ${ }^{11-13}$

\begin{tabular}{c|c|c|c|c}
\hline \multirow{2}{*}{ Phytochemicals } & \multirow{2}{*}{$\begin{array}{c}\text { This Research } \\
\text { Bogor, West Java }\end{array}$} & $\begin{array}{c}\mid c \\
\text { Imphal, Manipur }\end{array}$ & Amritsar, Punjab $^{12}$ & $\begin{array}{c}\text { Achankamar, } \\
\text { Bilaspur }^{13}\end{array}$ \\
\cline { 3 - 5 } & + & + & + & + \\
\hline Flavonoids & + & + & $\mathrm{NT}$ & + \\
\hline Tannins & + & + & + & + \\
\hline Terpenoids & - & + & $\mathrm{NT}$ & + \\
\hline Steroids & + & + & + & + \\
\hline Alkaloids & + & - & + & + \\
\hline Saponins & & & & + \\
\hline
\end{tabular}

Note: $+=$ presence; $-=$ absence; $\mathrm{NT}=$ not tested

The fractionation and purification of ethanol extract using various chromatography techniques had directed to the isolation of two phenolic compounds (fractions $\mathrm{C} 1$ and $\mathrm{F} 1$ ), which were characterized as curcumin (1) and naringenin (2), respectively, based on UV-Vis, FTIR, and LC-MS/MS spectral data. The structures of phenolics isolating from the rhizome of Indonesian C. amada are shown in Fig.-1.<smiles>COc1cc(/C=C/C(=O)CC(=O)/C=C/c2ccc(O)c(OC)c2)ccc1O</smiles>

(1)<smiles>O=C1CC(c2ccc(O)cc2)Oc2cc(O)cc(O)c21</smiles>

(2)

Fig.-1: Phenolics from ethanol extract of Indonesian C. amada rhizomes

Compound 1 (fraction C1) was obtained as a yellow-orange solid and showed strong absorption in the UVVis spectrum at the wavelength of 259 and $420 \mathrm{~nm}$. Am absorbed peak at $259 \mathrm{~nm}$ specified benzoyl chromophore, while another absorbed peak at $420 \mathrm{~nm}$ (visible) corresponded to a typical curcuminoid chromophore. ${ }^{9}$ This spectrum exhibits in agreement with previous reports. ${ }^{14-16}$ Furthermore, the FTIR spectrum of 1 displayed characteristic peaks of phenolics at the wavenumber of 3300, 3050, 1508, and 1282 $\mathrm{cm}^{-1}$ designated $\mathrm{O}-\mathrm{H}, \mathrm{C}-\mathrm{H} s p^{2}, \mathrm{C}=\mathrm{C}$ (aromatic), and C-O-C (ether), correspondingly. Furthermore, in order, the peaks at 2900-2800, 1718, and $1626 \mathrm{~cm}^{-1}$ for $\mathrm{C}-\mathrm{H} s p^{3}, \mathrm{C}=\mathrm{O}$, and $\mathrm{C}=\mathrm{C}$ (olefin) were also observed. A peak at $1718 \mathrm{~cm}^{-1}$ was characterized as a conjugated ketone with intramolecular hydrogen bond due to tautomerization of keto-enol and specific for $1 .{ }^{17}$ For extensive investigation, LC-MS/MS spectral data of 1 was analyzed and exhibited one major peak in LC chromatogram at the retention time of $8.71 \mathrm{~min}$. MS spectra depicted the typical MS peak for $1\left(\mathrm{C}_{21} \mathrm{H}_{20} \mathrm{O}_{6}\right)$, corresponding to the molecular ion of $369.1335 \mathrm{~m} / \mathrm{z}$ $[\mathrm{M}+\mathrm{H}]^{+}$as a base peak. Moreover, typical fragmented peaks of $\mathbf{1}$ at 353.2192, 335.2071, 285.1118, 253.0864, 245.0811, 193.0652, 177.0548, 149.0597, 145.0285, 135.0364, 117.0335, and $91.0539 \mathrm{~m} / \mathrm{z}$ were also observed. ${ }^{18-19}$ The fragmentation scheme of $\mathbf{1}$ is presented in Figure 2. Compound $\mathbf{1}$ has been isolated previously from acetone extract of the rhizome of Indian C. amada. ${ }^{20}$ Furthermore, Curcumin is a major activity of the spice turmeric, $C$. longa ${ }^{17,19,21-23}$ It has also been identified as well as $C$. wenyujin and $C$. domestica. ${ }^{18,24}$

Compound 2 (fraction F1) was afforded as pale-yellow solid. The UV-Vis spectrum of 2 exhibited the maximum absorbance, which corresponds to characteristic peaks of flavanone at the wavelength of 283 and 
RASĀYAN J. Chem.

Vol. 14 | No. 4 |2686-2691| October- December | 2021

$334 \mathrm{~nm}$ fit to benzoyl and cinnamoyl chromophore, respectively. ${ }^{25}$ The widening of absorption at the wavelength of $300-500 \mathrm{~nm}$ is probably due to the presence of curcuminoid compounds. Moreover, typical absorption peaks of the phenolic compound were also observed in the FTIR spectrum of 2, i.e. O-H, C-H $s p^{2}, \mathrm{C}=\mathrm{C}$ (aromatic), and $\mathrm{C}-\mathrm{O}-\mathrm{C}$ (ether) at the wavenumber of 3336, 2961, 1681-1617, and $1274 \mathrm{~cm}^{-1}$, respectively. Besides, the FTIR spectrum of 2 also showed absorbed peaks at 2927-2872 and $1730 \mathrm{~cm}^{-1}$ specified $\mathrm{C}-\mathrm{H} s p^{3}$ and $\mathrm{C}=\mathrm{O}$, respectively, revealing flavanone. To support $\mathrm{UV}$-Vis and FTIR analysis, LCMS/MS was carried out and showed one dominant peak at the LC chromatogram at the retention time of $5.79 \mathrm{~min}$. According to MS spectrum, 2 showed a molecular ion peak at $273.1168 \mathrm{~m} / \mathrm{z}[\mathrm{M}+\mathrm{H}]^{+}$which correspond to $\mathrm{C}_{15} \mathrm{H}_{12} \mathrm{O}_{5}$ and fragmented peaks at 257.1393, 239.1284, 229.1432, 217.1591, 201.0760, 175.0600, 161.0959, 157.1009, 135.0804, 119.0857 (base peak), 107.0855, 91.0545, and $79.0544 \mathrm{~m} / \mathrm{z}$ with the fragmentation scheme is summarized in Fig.-3. The fragmented peaks indicated the fragmentation pattern of flavanone. ${ }^{26-30}$ Compound 2 was isolated from C. zedoaria rhizomes and Zingiber officinale Roscoe. ${ }^{30-31}$ This compound has been reported to be effective in modulating gastric ulcers. ${ }^{32}$

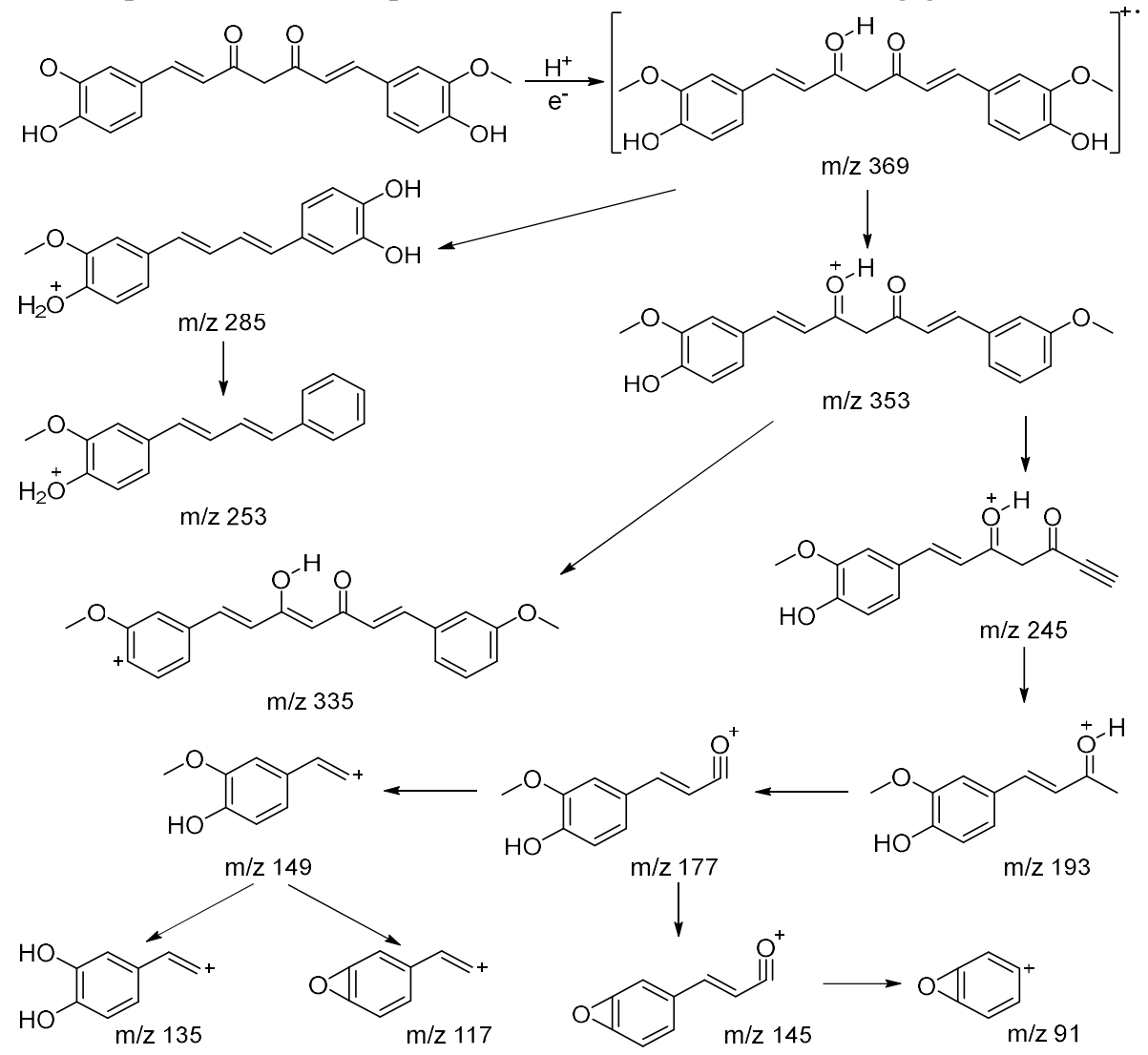

Fig.-2: Fragmentation Scheme of 1

\section{CONCLUSION}

Phytochemical constituents from the rhizomes of Indonesian $C$. amada were successfully macerated in ethanol with $5.084 \%(\mathrm{w} / \mathrm{w})$ in yield. A preliminary study on phytochemical constituents of $C$. amada rhizomes exhibited the presence of flavonoid, tannin, terpenoid, alkaloid, and saponin. Phenolic compounds from its ethanol extract were successfully isolated and characterized as curcumin and naringenin. The continued research should be conducted to isolate other secondary metabolites and evaluate their pharmacological activities to contribute scientific validation of bioactive phytochemicals in correlation with C. amada in traditional medicine.

\section{ACKNOWLEDGEMENT}

The authors would like to express gratitude to the Ministry of Research and Technology for supporting and funding this research through Penelitian Dasar Unggulan Perguruan Tinggi (PDUPT) 2020 No. 1/E1/KP.PTNBH/2020 and No. 1/AMD/E1/KP.PTNBH/2020 (amendment). 
RASĀYAN J. Chem.

Vol. 14 | No. 4 |2686-2691| October-December | 2021

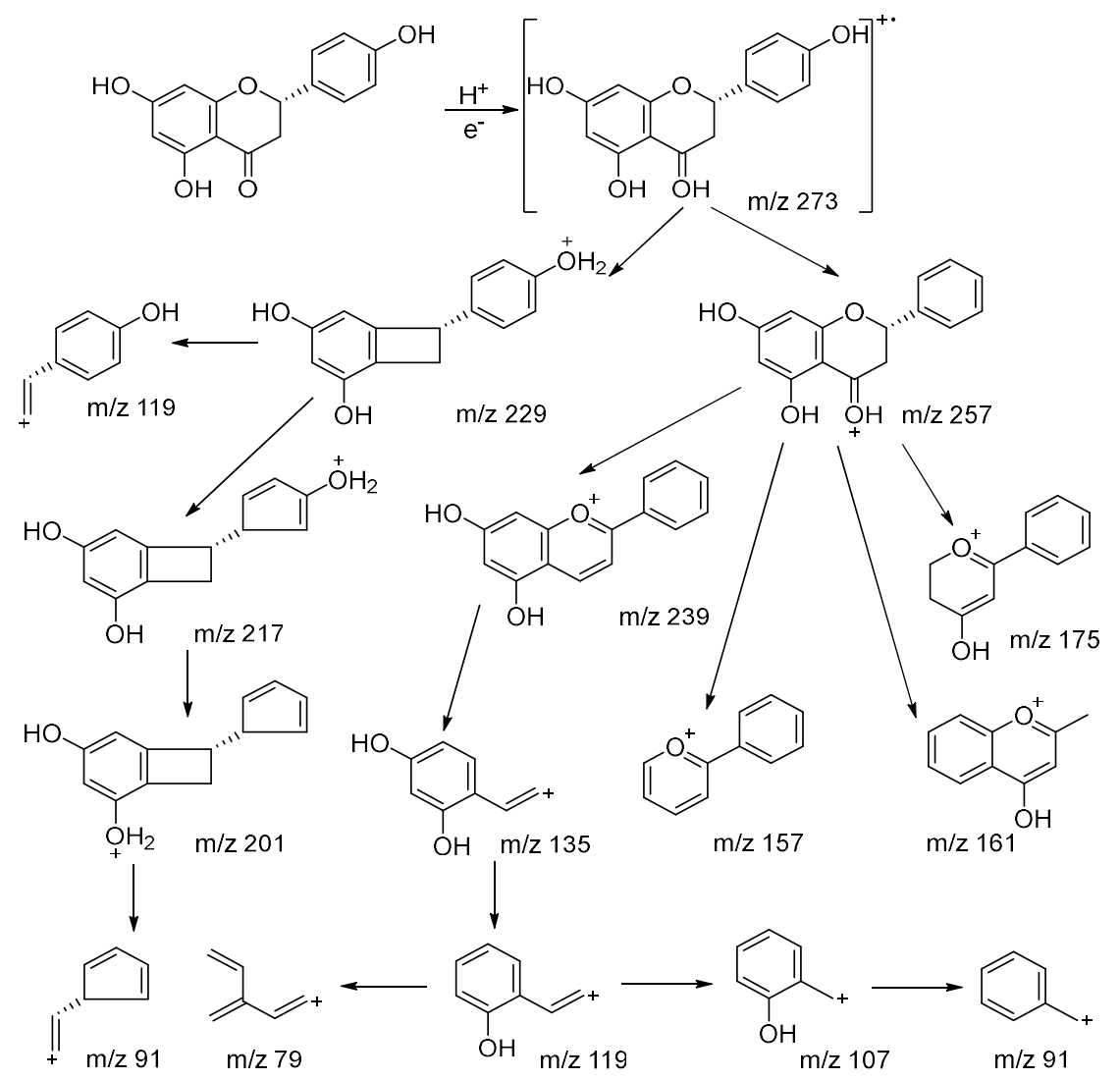

Fig.-3: Fragmentation Scheme of 2

\section{REFERENCES}

1. J. Mishra, A. Bhardwaj and K Misra, Management of High Altitude Pathophysiology, 153-169 (2018), DOI:10.1016/B978-0-12-813999-8.00008-2

2. T. S. Al-Qudah, S. A. Malloh, A. Nawaz, M. A. Ayub, S. Nisar, M. I. Jilani and T S Al-Qudah, International Journal of Chemical and Biochemical Sciences, 11, 51(2017).

3. S. N. A. Malek, G. S. Lee, S. L. Hong, H. Yaacob, N. A. Wahab, J-F. F. Weber and S. A. A. Shah, Molecules, 16(6), 4539(2011), DOI:10.3390/molecules16064539.

4. Tg S. A. Tg Kamazeri, O. A. Samah, M. Taher, D. Susanti and H. Qaralleh, Asian Pacific Journal of Tropical Medicine, 5(3), 202(2012), DOI:10.1016/S1995-7645(12)60025-X.

5. K. C. Wong, T. C. Wong and S. G. Chee, Journal of Essential Oil Research, 11(3), 349(1999), DOI: $10.1080 / 10412905.1999 .9701151$.

6. I. R. A. Wahab, P. D. Blagojević, N. S. Radulović and F Boylan, Chemistry \& Biodiversity, 8(11), 2005(2011), DOI:10.1002/cbdv.201100135.

7. R. S. Policegoudra, S. Divakar and S. M. Aradhya, Journal of Applied Microbiology, 102(6), 1594(2007), DOI:10.1111/j.1365-2672.2006.03186.x.

8. R. S. Policegoudra, K. Rehna, L. J. Rao and S. M. Aradhya, Journal of Biosciences, 35, 231(2010), DOI:10.1007/s12038-010-0027-1.

9. D. U. C. Rahayu, D. A. Setyani, H. Dianhar and P. Sugita, Asian Journal of Pharmaceutical and Clinical Research, 13(7), 194(2020) DOI:10.22159/ajpcr.2020.v13i7.38249.

10. D. A. Setyani, D. U. C. Rahayu, S. Handayani and P. Sugita, IOP Conference Series: Materials Science and Engineering, 902, 012066 (2020) DOI:10.1088/1757-899X/902/1/012066.

11. T. S. Singh, I. T. Phucho and T. B. Singh, World Journal of Pharmaceutical Research, 4(8), 2286(2015).

12. R Kaur, B. Kaur, A. Suttee and V. Kalsi, Asian Journal of Pharmaceutical and Clinical Research, 11(2), 94(2018) DOI:10.22159/ajpcr.2018.v11s2.28591. 


\section{RASĀYAN J. Chem.}

Vol. 14 | No. 4 |2686-2691| October- December | 2021

13. M. Hait and J. Deepak, Journal of Pharmacognosy and Phytochemistry, 7(6), 1306(2018).

14. H. V. Nong, L. X. Hung, P. N. Thang, V. D. Chinh, L. V. Vu, P. T. Dung, T. V. Trung and P. T. Nga, SpringerPlus, 5, 1147(2016), DOI:10.1186/s40064-016-2812-2.

15. B. Cahyono, J. Ariani, H. Failasufa, M. Suzery, S. Susanti and H. Hadiyanto, Rasayan Journal of Chemistry, 12(1), 7(2019) DOI:10.31788/RJC.2019.1213092.

16. E. Halevas, A. Pekou, R. Papi, B. Mavroidi, A. G. Hatzidimitriou, G. Zahariou, G. Litsardakis, M. Sagnou, M. Pelecanou and A. A. Pantazaki, Journal of Inorganic Biochemistry, 208, 111083(2020), DOI:10.1016/j.jinorgbio.2020.111083.

17. A. B. D. Nandiyanto, A. S. Wiryani, A. Rusli, A. Purnamasari, A. G. Abdullah, Ana, I. Widiaty and R. Hurryati, IOP Conference Series: Materials Science and Engineering, 180, 012136(2017), DOI:10.1088/1757-899X/180/1/012136.

18. M. Hao, D. Ji, L. Li, L. Su, J. Zhang, Q. Wang, W. Gu, C. Jiang, T. Lu and C. Mao, Pharmacognosy Magazine, 15(60), 164(2019), DOI:10.4103/pm.pm_399_18.

19. N. Nurjanah and E. Saepudin, AIP Conference Proceedings, 2168, 020065(2019), DOI: $10.1063 / 1.5132492$.

20. A. P. Gupta, M. M. Gupta and S. Kumar, Journal of Liquid Chromatography \& Related Technologies, 22(10), 1561(1999), DOI:10.1081/JLC-100101751.

21. B. Kocaadam and N. Şanlier, Critical Reviews in Food Science and Nutrition, 57(13), 2889(2017), DOI:10.1080/10408398.2015.1077195.

22. F. Sahne, M. Mohammadi, G. D. Najafpour and A. A. Moghadamnia, Industrial Crops and Products, 95, 686(2017), DOI:10.1016/j.indcrop.2016.11.037.

23. Md. M. Rahaman, A. Rakib, S. Mitra, A. M. Tareq, T. B. Emran, A. F. M. Shahid-Ud-Daula, M. N. Amin, and J. Simal-Gandara, Plants, 10(1), 63(2021), DOI:10.3390/plants10010063.

24. M. Lechtenberg, B. Quandt and A. Nahrstedt, Phytochemical Analysis, 15(3), 152(2004), DOI: $10.1002 /$ pca. 759 .

25. D. Tsimogiannis, M. Samiotaki, G. Panayotou and V. Oreopoulou, Molecules, 12(3), 593(2007), DOI: $10.3390 / 12030593$.

26. X. Zeng, W. Su, Y. Zheng, H. Liu, P. Li, W. Zhang, Y. Liang, Y. Bai, W. Peng and H. Yao, Molecules, 23(4), 895(2018), DOI:10.3390/molecules23040895.

27. Y. Chen, H. Yu, H. Wu, Y. Pan, K. Wang, Y. Jin and C. Zhang, Molecules, 20(10), 18352(2015), DOI:10.3390/molecules201018352.

28. F. Xu, Y. Liu, Z. Zhang, C. Yang and Y. Tian, Chinese Medicine, 4, 15(2009), DOI:10.1186/17498546-4-15.

29. N. Fabre, I. Rustan, E. de Hoffmann and J. Quetin-Leclercq, Journal of the American Society for Mass Spectrometry, 12(6), 707(2001), DOI:10.1016/S1044-0305(01)00226-4.

30. S. Eun, I. Choi and S. H. Shim, Bulletin of the Korean Chemical Society, 31(5), 1387(2010), DOI:10.5012/bkcs.2010.31.5.1387.

31. A. Ghasemzadeh, H. Z. E. Jaafar and A. Rahmat, Molecules, 15(6), 4324(2010), DOI:10.3390/molecules15064324.

32. M. Gonzales-Uscamayta, J. E. Chavez-Flores, H. Obregon-Tinoco, F. P. Cardenas-Toro, M. J. Simirgiotis, J. Borquez and J. Robles-Caycho, Rasayan Journal of Chemistry, 13(4), 2455(2020) DOI:10.31788/RJC.2020.1345955.

[RJC-6581/2021] 